\title{
PEMBERONTAKAN BOSNIA HERZEGOVINA 1875 : ANALISIS KE ATAS PERANAN SERBIA
}

\author{
Azlizan Mat Enh
}

\section{Pendahuluan}

Masyarakat Bosnia Herzegovina terdiri daripada rumpun Slav yang berhijrah ke Semenanjung Balkan pada abad ke-7 M. Di bahagian utara, barat dan selatan Bosnia Herzegovina yang bersempadan dengan Croatia, manakala di bahagian selatan dan timur pula bersempadan dengan Serbia yang juga daripada rumpun Slav. ${ }^{1}$ Masyarakat Slav di Semenanjung Balkan ini dikenali sebagai Slav Selatan. Mereka merupakan salah satu daripada komponen Slav dari beberapa bahagian Slav di Eropah Timur iaitu, bangsa Slav Timur (Rusia dan Ukrain) dan Slav Barat (Poland dan Czecholovakia). ${ }^{2}$

\section{Bosnia Herzegovina Di Bawah Pentadbiran Uthmaniyah}

Bosnia Herzegovina mula berada di bawah jajahan kerajaan Uthmaniyah pada tahun 1463. Ini ekoran daripada perluasan kuasa kerajaan Uthmaniyah di Semenanjung Balkan selepas kekalahan tentera Serbia ke tangan tentera kerajaan Uthmaniyah dalam Perang Kosovo ${ }^{3}$ yang meletus pada tahun 1389. Penaklukan kerajaan Uthmaniyah ke atas Bosnia Herzegovina, menandakan bermulanya era pemerintahan kerajaan Islam di Bosnia Herzegovina dan berakhirnya empayar Dushan yang dinaungi oleh Raja Karageogvitch dari Serbia. 
Pentadbiran kerajaan Lthmaniyah di Bosnia Herzegovina diterima baik oleh mastarakat di sana. Malah, penduduk Bosnia Herzegovina vang sebahagiannya menganut agama Kristian Bogomil telah memeluk agama Islam. Manakala penganut Kristian Katolik lebih selesa berada di bawah jajahan kerajaan Islam L'thmaniyah daripada berada di bawah jajahan kerajaan Serbia. Ini kerana agama Kristian Ortodok mendapat keistimewaan semasa penjajahan Serbia, manakala agama-agama lain seperti Kristian Katolik sering ditindas. Bagi masvarakat Kristian Ortodok pula, pemerintahan kerajaan Islam L'thmanivah adalah lebih baik berbanding pemerintahan kerajaan Kristian Katolik Byzantin yang pernah memerintah Bosnia Herzegorina pada abad ke 18 .

\section{Pemberontakan Bosnia 1875}

Penerimaan masyarakat Bosnia Herzegovina terhadap kerajaan Uthmanivah, membolehkan kerajaan Islam memerintah negeri tersebut selama hampir empat ratus tahun. Walau bagaimanapun pada tahun 1875 , telah meletusnya pemberontakan menentang kerajaan Uthmanivah di Bosnia Herzegovina. Pemberontakan yang bermula di daerah Nevessin, Herzegovina, akhirnya telah bertukar kepada peperangan antara Muslim dan Kristian di seluruh Bosnia Herzegovina. Tujuan utama pemberontakan tersebut adalah untuk menghapuskan pemerintahan daulat Uthmaniyah dan menggantikannya dengan kerajaan Kristian. Kecenderungan untuk menghapuskan kerajaan Uthmaniyah menyebabkan pelbagai masalah telah ditimbulkan di Bosnia Herzegovina oleh masyarakat Kristian. Antaranya, mengenai isu pentadbiran di Bosnia Herzegovina yang mempraktikkan ajaran Islam. Mereka mendakwa bahawa undang-undang Islam tidak releran dipraktikkan di Bosnia Herzegovina dan merupakan salah satu punca penentangan Kristian Bosnia Herzegovina ke atas kerajaan Uthmaniyah.

Keadaan huru-hara yang meletus di Bosnia Herzegovina dapat dibahagikan kepada dua peringkat. Pada mulanya ia merupakan kekacauan yang dicetuskan oleh beberapa orang Kristian Serb yang tidak lebih daripada 10 orang sahaja di wilayah Nevessin di Herzegovina. ${ }^{4}$ Namun begitu, kekacauan yang tidak ditangani dengan segera telah bertukar kepada pemberontakan yang semakin mengganas dan merebak hingga ke wilayah-wilayah lain dengan jumlah pengikut yang semakin ramai.

Pemberontakan bermula di Herzegovina selepas $164^{\text {orang }}$

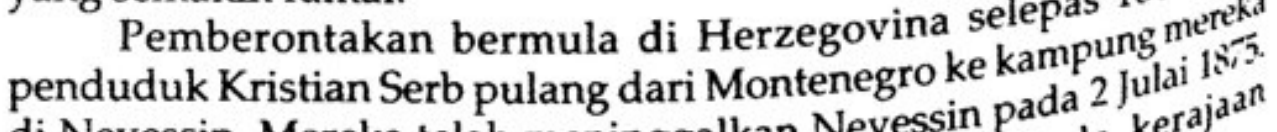

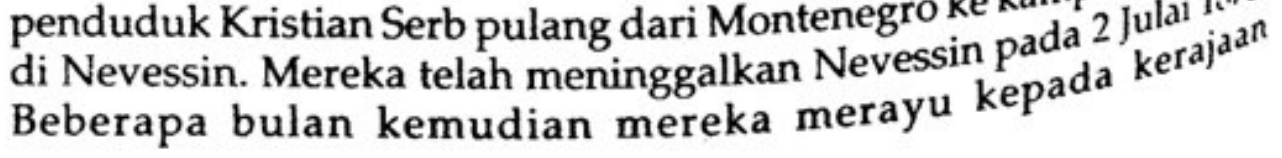


Uthmaniyah untuk pulang semula ke Neressin. Setelah kembali ke Nevessin kumpulan ini telah memulakan kekacauan dengan menghasut jiran-jiran mereka untuk menentang kerajaan Uthmanivah. Antaranya, mereka tidak mahu menjelaskan cukai kepada kerajaan dan tuan tanah, memboikot bidang pertanian serta tidak mengakui kekuasaan polis-polis di daerah mereka. ${ }^{5}$ Bagi menyelesaikan kekacauan tersebut, kerajaan Uthmaniyah telah menghantar Haidar Bey dan Petrarchi Effendi dari Sarajevo untuk berunding dan meneliti tuntutan-tuntutan pemberontak. Namun begitu, sebelum ketibaan kedua-dua orang wakil itu, pemberontak telah bertindak ganas dengan menyerang dan membunuh ramai orang awam.

Ketua mereka yang bernama Tchoubate, telah membahagikan kumpulannya yang terdiri daripada 300 orang pengikut kepada beberapa kumpulan kecil. Ini dilakukan supaya dapat menyekat dan menyerang orang ramai yang melalui beberapa jalan di daerah berhampiran seperti di Kruppa, Mostar dan Meteovich. Mereka melakukan keganasan kepada sesiapa yang enggan mengikuti kegiatan mereka. Pemberontak ini telah memusnahkan rumah-rumah dan harta benda sebagai cara untuk menakut-nakutkan penduduk. Di dalam serangan tersebut, pemberontak-pemberontak Kristian telah melakukan kekejaman dengan memancung kepala lima orang mangsa yang terdiri daripada pedagang-pedagang Muslim yang sering berulang alik dari Mostar ke Nevessin. Pedagang-pedagang Muslim itu dikenali sebagai Salih, Kassumovich, Marich Samich, Ali dan seorang lagi yang tidak dikenal pasti namanya, tetapi dipercayai berasal daripada Hrasne. Selain itu, menurut laporan Pesuruhjaya dari Mostar, banyak mayat orang Islam yang telah dijumpai ditanam tanpa berkepala.

Pembunuhan yang meletus pada Julai 1875 ini telah membangkitkan semangat assabiyah di kalangan orang Islam di Mostar. Mereka ingin membalas dendam di atas kekejaman yang dilakukan terhadap orang Islam tetapi telah dihalang oleh kerajaan Uthmaniyah. Tujuannya adalah untuk mengelakkan pertumpahan darah yang teruk dan kehilangan nyawa yang ramai di antara orang Kristian dan Islam. Sebaliknya mereka diminta menyerahkan tanggungjawab tersebut kepada pihak berkuasa.

Rundingan seterusnya di antara wakil kerajaan dengan ketua pemberontak telah diadakan pada 16 Julai 1875. Hassan Pasha dan Petrarchi Effendi, selaku wakil kerajaan telah memberikan jaminan kepada pemberontak, bahawa kerajaan akan meneliti setiap tuntutan dan perasaan tidak puashati tersebut dengan syarat mereka memberhentikan kegiatan subversif dan meletakkan senjata. ${ }^{7}$ Sebaliknya, pemberontak enggan meletakkan senjata selagi kerajaan tidak memenuhi tuntutan mereka di antara lain membenarkan mereka untuk memiliki senjata. 
Pihak kerajaan tidak dapat menunaikan permintaan mereka. Kerajaan Uthmaniyah memerlukan masa yang secukupnya untuk membuat siasatan dan mengkaji tuntutan yang dibuat oleh mereka. Keengganan pemberontak untuk melucutkan senjata telah meletakkan wilayah tersebut dalam keadaan yang terancam dan sukar dikawal. Keadaan ini menyebabkan kerajaan Uthmaniyah mengarahkan tujuh hingga lapan batalion tentera simpanannya untuk menumpaskan kekacauan di kampung-kampung yang terlibat seperti di Belgrade dan Selvidor di Nevessin, tetapi langkah ini sudah tidak berkesan untuk menyekat dan menumpaskan kegiatan pemberontak kerana jumlah pengikut mereka telah bertambah ramai. ${ }^{8}$ Sokongan ini menyebabkan tindakan mereka semakin berani untuk melakukan keganasan terhadap orang Muslim dan sesiapa sahaja yang tidak bersetuju dengan perjuangan mereka.

Langkah pihak kerajaan Uthmaniyah yang tidak mahu menggunakan kekerasan serta tidak menghantar angkatan tentera pada peringkat awal untuk menumpaskan kegiatan pemberontak adalah untuk mengelakkan rakyat yang tidak terlibat daripada mengalami kecederaan. Sebaliknya, kerajaan menggunakan pendekatan diplomasi dengan menghantar beberapa orang yang berpengaruh dari wilayah Sarajevo seperti Haidar Bey dan Effendi Petrarchi untuk berunding dan menenangkan mereka. Sikap kerajaan yang bertolak ansur dan tidak memandang serius telah membuka peluang kepada pemberontak untuk menggiatkan penentangan mereka ke atas orang Islam.

Kejadian yang bermula dengan kekacauan dan huru-hara telah bertukar sehingga ke tahap pemberontakan di Herzegovina. Pada 6 Ogos 1875 , telah meletus satu pemberontakan yang semakin ganas di Herzegovina. Orang-orang Kristian telah membakar rumah orang Islam dan memusnahkan tanah pertanian mereka. Di samping itu, mereka turut bertempur dengan 1,000 orang tentera kerajaan yang ditugaskan di Nevessin. Keganasan dan keangkuhan jelas telah menguasai diri para pemberontak tersebut. Ini menyebabkan kerajaan terpaksa menghantar tiga hingga lima batalion tentera untuk menyelamatkan keadaan di sana. ${ }^{9}$

Pada masa yang sama, meletus satu lagi pemberontakan yang serius pada 16 Ogos, 1875 di wilayah Gradiska, Bosnia. Pemberontakan tersebut disebabkan hasutan seorang banduan yang telah berjaya melarikan diri dari pihak Bosnia. Penjenayah ini telah menghasut ramai orang Kristian supaya menimbulkan kekacauan dan menentang kerajaan Uthmaniyah. Akibat keselamatan penduduk yang terancam, ramai orang Islam dan Kristian yang tidak mahu terlibat telah keluar mencari perlindungan di Austria. Di dalam kejadian itu, banyak rumah dan harta benda yang musnah. Namun begitu, menurut laporan akhbar Slav mereka menuduh bahawa Semua Islam yang bertanggung jawab di atas kejadian tersebut. Semu 
maklumat telah disalah tafsir oleh akhbar dengan menutup kejahatan yang dilakukan oleh orang Kristian. ${ }^{10}$

Selepas peristiwa itu, keadaan pemberontakan di Bosnia bertambah ganas dan biadap. Penentangan yang bermula dengan pemberontakan telah bertukar kepada peperangan. Di Klek, mereka telah membakar rumah-rumah orang Islam dan Kristian yang tidak mengikuti kegiatan mereka. Mereka telah bersikap kejam terhadap semua orang Islam termasuk wanita dan kanak-kanak. Di antaranya mereka telah melakukan perbuatan di luar batas-batas kemanusiaan di mana dua orang kanak-kanak yang tidak berdosa telah dipanggang hingga mati oleh pemberontak-pemberontak Kristian Serb. "Tanamantanaman dan rumah-rumah mereka turut dimusnahkan. Ini sekali lagi memaksa orang ramai melarikan diri dalam keadaan sehelai sepinggang untuk mencari perlindungan di negeri-negeri jiran seperti Dalmatia, Montenegro, Crotia, Serbia dan Austria. Jumlah pelarian di Bosnia Herzegovina pada 1875, akibat kekejaman orang Kristian dianggarkan seramai 156,000 orang. ${ }^{12}$

Memandangkan kegiatan pemberontakan bertambah serius di Bosnia Herzegovina, pada 30 Mac 1876, Gabenor telah meminta pihak pemberontak supaya meletakkan senjata dan membuat tawaran kepada mereka supaya menyerah diri. Di antara tawaran yang diberikan ialah sesiapa yang menyerah diri secara sukarela akan diberikan pengampunan secara beramai-ramai, diberi pengecualian pembayaran cukai selama setahun dan kerajaan juga berjanji untuk mengkaji semula isu-isu yang berkaitan dengan ketidakpuasan hati penduduk di Bosnia Herzegovina terutamanya dengan sistem percukaian di wilayah tersebut. ${ }^{13}$

Bagaimanapun, rundingan gagal kerana pemberontak enggan menerima tawaran yang diberikan oleh kerajaan. Sebaliknya mereka mengemukakan beberapa tuntutan ke atas kerajaan Uthmaniyah. Antaranya ialah orang Kristian perlu diberi 1/3 daripada tanah kerajaan, mengeluarkan tentera dari Bosnia Herzegovina, membina semula rumah-rumah dan gereja yang telah musnah, memberi bantuan makanan selama setahun, meletakkan dahulu senjata sekiranya mahu orang Kristian berbuat demikian. ${ }^{14}$

Selain itu, pihak pemberontak menuntut supaya kuasa-kuasa besar di Eropah, campur tangan dan memberi jaminan bahawa kerajaan Uthmaniyah akan melaksanakan perubahan di dalam pentadbiran dan pengurusan. Di samping itu, mereka juga meminta supaya kerajaan Rusia dan Austria bertanggungjawab mengawasi keadaan reformasi yang dilaksanakan di Bosnia Herzegovina oleh kerajaan Uthmaniyah. Sebaliknya, kerajaan Uthmaniyah berkeyakinan bahawa masalah dalaman ini mampu diselesaikan dengan baik tanpa campurtangan mana-mana pihak. Tambahan pula, campurtangan luar hanya menunjukkan kelemahan mentadbir empayarnya sendiri dan 
merupakan penghinaan kepada kerajaan Uthmaniyah.

Keputusan yang dibuat oleh pemberontak menunjukkan mereka tidak mahu memberi peluang dan bekerjasama dengan kerajaan untuk mengembalikan keamanan di Bosnia Herzegovina. Sekiranya mereka telah ditindas oleh kerajaan Uthmaniyah, tawaran daripada kerajaan merupakan satu peluang yang sepatutnya dihargai. Perdamaian antara pemberontak dengan kerajaan Uthmaniyah tidak berjaya kerana rancangan Serbia yang ingin membuktikan bahawa kerajaan Ottoman gagal menyelesaikan konflik di Bosnia Herzegovina.

\section{Kepentingan Bosnia Kepada Serbia}

Keinginan Serbia untuk membalas dendam terhadap kerajaan Uthmaniyah telah lama berakar umbi dalam sejarah pemerintahan Serbia. Ini adalah ekoran kekalahan mereka ke tangan kerajaan Uthmaniyah pada 1389 dalam peperangan Kosovo. Kejayaan kerajaan Uthmaniyah di Kosovo, bukan sahaja menjatuhkan empayar Serbia, tetapi membolehkan Islam bertapak di Balkan dan meletakkan bangsa Slav dan penganut Ortodok di bawah pengaruh Islam. Sebelum Perang Kosovo, Bosnia Herzegovina adalah di bawah pentadbiran Serbia. Walaupun kerajaan Serbia telah tewas kepada kerajaan Uthmaniyah tetapi usaha-usaha untuk mendapatkan semula Bosnia Herzegovina sentiasa dijalankan oleh Serbia demi mengembalikan keagungan empayar Serbia dalam rancangan Serbia Raya dan agama Ortodok.

Serbia Raya yang dirancang oleh Serbia adalah penggabungan negeri-negeri Slav di Semenanjung Balkan terutamanya Bosnia Herzegovina di bawah naungan kerajaan Serbia. Antara faktor penting yang melibatkan Bosnia adalah: pertama, kedudukan geografi Bosnia Herzegovina yang berjiran dengan Serbia, tanpa Bosnia Herzegovina, adalah sukar kepada Serbia untuk membentuk Serbia Raya. Tambahan pula, masyarakat Bosnia Herzegovina adalah terdiri daripada rumpun Slav yang sama seperti Serbia dan mempunyai jumlah penduduk Kristian Serb yang ramai. Di samping itu, mereka juga menuturkan bahasa yang sama dengan masyarakat Serb di Serbia serta mengamalkan ajaran Kristian Ortodok. Oleh itu, penyatuan Serbia dan Bosnia Herzegovina akan membolehkan mereka terikat sebagai satu bangsa dan satu agama. Dalam erti kata lain, dapat membentuk sebuah kerajaan Serbia yang homogeni. Bahkan bagi orang-orang Serb, agama Ortodok seharusnya superior daripada agama-agama lain di Balkan. Pentadbiran kerajaan Islam di Bosnia Herzegovina dianggap sebagai ancaman kepada agama Ortodok. ancaman kepada agama Ortodok.
Kedua, Bosnia Herzegovina merupakan wilayah laluan keluar
ke Laut Adriatik, iaitu salah satu laluan strategik yang penting dalam 
bidang pertahanan dan perdagangan antarabangsa. Oleh itu, Bosnia Herzegovina akan menjadi nadi kepada masa depan perkembangan ekonomi Serbia. Ini kerana Serbia tidak mempunyai pelabuhan antarabangsa yang memudahkan Serbia memasarkan barang dagangannya ke negara-negara Eropah yang lain. Sehubungan dengan itu, Serbia bergantung kepada sistem pengangkutan darat untuk tujuan pengeksportan hasil pertaniannya.

Ketiga, Serbia juga bercita-cita untuk menakluki bangsa-bangsa Slav yang lain seperti di Slovenia, Croatia dan Dalmatia secara berperingkat untuk disatukan dengan Serbia. Kesemua negeri-negeri Slav ini akan didominasi dan diperintah oleh Serbia di bawah naungan Dinasti Karageoragevich. Mengikut idea Serbia Raya ini, negeri-negeri Slav tersebut akan berkongsi perlembagaan yang digubal oleh kerajaan Serbia dan menggunakan sistem pendidikan yang tidak bertentangan dengan dasar kerajaan Serbia. Tujuan Serbia ini adalah untuk memelihara dan menjaga perlembagaan serta tradisi kerajaan Serbia di samping dapat menjadi pemimpin kepada negeri-negeri Slav yang lain. Berdasarkan kepada alasan di atas, Serbia berusaha untuk melibatkan diri dalam pemberontakan di Bosnia Herzegovina, supaya ia dapat memenuhi cita-cita kebangsaan yang dimaksudkan.

\section{Peranan Serbia}

Bagi mencapai cita-cita Serbia Raya, Serbia telah berusaha menimbulkan permusuhan antara orang Kristian di Bosnia Herzegovina dengan kerajaan Uthmaniyah. Sebelum meletusnya pemberontakan di Bosnia Herzegovina pada tahun 1875, penyokongpenyokong pemberontak Serbia, sering berulang alik dari Serbia ke wilayah Bosnia Herzegovina seperti di Wichgard, Zwornick dan di Novi Bazar. Mereka cuba membawa masuk senjata dan tentera ke Sarajevo untuk mencetuskan rusuhan tetapi berjaya dihalang oleh kerajaan Uthmaniyah di Bosnia Herzegovina. ${ }^{15}$ Namun begitu, usaha tersebut tidak berakhir di situ sahaja, sebaliknya mereka telah menggiatkan usaha dalam menghasut masyarakat Kristian Serb di Bosnia Herzegovina untuk menentang kerajaan Uthmaniyah pada tahun 1875.

Justeru, bagi menarik perhatian kerajaan, mereka telah menimbulkan kekacauan di beberapa daerah di Bosnia Herzegovina dengan melakukan perbuatan keji seperti melibatkan diri dalam rompakan dan pergaduhan dengan orang Islam. Tujuannya adalah untuk mendapat tindakbalas dari tentera Islam agar terlibat dalam konflik dengan mereka. 
Pemberontakan di Bosnia Herzegovina bukanlah inisiatif masyarakat Bosnia Herzegovina, sebaliknya ia adalah konspirasi yang dirancang oleh Serbia. Serbia telah memainkan peranan sebagai agen kepada Rusia dalam propaganda I'an Slav di Semenarjung Batkan termasuk di Bosnia Herzegovina. Propaganda Pan Slav ini gjat dilaksanakan oleh Serbia dengan menyeru supaya semua orang Kristian bangun memberontak terhadap kerajaan Uthmaniyah. Serbia juga telah mengatur pertubuhan-pertubuhan sulit secara rahsia di kalangan penganut-penganut Kristian Ortodok untuk menentang kerajaan Uthmaniyah. Serbia dengan sokongan Rusia, merancang dan bersiap sedia untuk melancarkan pemberontakan ke atas kerajaian Uthmaniyah apabila mendapat pemimpin yang sesuaj."

Suratkhabar-suratkhabar di Serbia turut menyebarkan beritaberita palsu mengenai penindasan kerajaan Uthmaniyah terhadap orang Kristian Bosnia Herzegovina. Mereka juga menuduh bahawa orang Bosnia Herzegovina menuntut hak autonomi ke atas Bosnia Herzegovina. Mereka berharap kuasa-kuasa besar akan mendengar permasalahan di Bosnia Herzegovina dan bersetuju menyerahkan Bosnia Herzegovina kepada Serbia. Hakikatnya, keadaan ini berbeza dengan laporan akhbar di wilayah itu. Penduduk di Bosnia sebenamya rakyat Bosnia Herzegovina masih ingin kekal di bawah jajahan kerajajan Uthmaniyah. Apa yang diharapkan oleh mereka adalah agar kerajaan Uthmaniah melaksanakan sistem pentadbiran yang lebih baik pada masa hadapan di Bosnia Herzegorina. (Penduduk di Bosnia telah dipaksa oleh pemberontak-pemberontak Serbja untuk menuntut autonomi daripada kerajaan Uthmaniyah)."

Serbia juga telah menyatakan sokongan sebulat suara terhadap pemberontakan di Bosnia Herzegovina. Mereka telah memberikan bantuan senjata kepada pemberontak-pemberontak di Bosnia Herzegovina. Segala alat-alat kelengkapan perang yang dimiliki dari simpanan kerajaan Serbia telah didapati dalam kem-kem pemberontak. ${ }^{18}$ Malah sebahagian besar pemberontak di bosnia Herzegovina adalah terdiri daripada pengganas Serbia, Montenegro dan Dalmatia.

Selain itu, Serbia juga telah memberikan sokongan moral kepada pengganas-pengganas di Bosnia Herzegovina. Serbia telah menaikkan semangat pemberontak-pemberontak ini dengan membuat laporanlaporan palsu bahawa mereka hampir mencapai kejayaan dalam usatha menentang kerajaan Uthmaniyah di Bosnia Herzegovina. Serbia juga mengingatkan pengganas-pengganas Kristian ini bahawa sattdara mereka iaitu Rusia akan turut memberi sokongan dan bantuan. Beg ith juga, parti-parti persendirian di Serbia turut memberikan kejjasan ${ }^{a}$ untuk membangkitan kekacauan di Bosnia Herzegovina.

Serbia juga mengambil peluang di atas kekacauan di Bosnia Herzegovina untuk melancarkan serangan ke atas kerajaan Uthmaniy ath 
di Bosnia Herzegovina. Serbia telah menggiatkan dan molatih angkatan tenteranya sebagai persediaan untuk menertang kerajaan Uthmaniyah..$^{14}$ Bagi menyusun angkatan tenteranya, mereka telah memperuntukkan sejumlah wang yang besar bagi menjayakan rancangan ini termasuk membantu pemberontak-pemberontak di Bosnia Herzegovina. Kegiatan ini telah dilakukan secara sulit. ?"

Pada Ogos 1875, Serbia telah menghantar seramai 40 orang tenteranya yang dilengkapi dengan senjata dan ubat-ubatan menyeberangi sempadan ke Bosnia Herzegovina. Tujuan mereka adalah untuk memberikan bantuan kepada pemberontak menentang kerajaan Uthmaniyah. Malah mereka telah diketuai oleh lima orang pegawai tentera Serbia." l'egawai tentera Serbia ini telah melatith pemberontak ini untuk menentang kerajaan Uthmaniyah. Keadaan ini menyebabkan jumlah orang Serbia yang memasuki Bosnia Herzegovina semakin bertambah. Pemberontak-pemberontak yang dilatih ini, telah memburukkan lagi keadaan di Bosnia Herzegovina dengan membantu dan menggalakkan pemberontak Kristian tempatan mencetuskan kekacauan di sana.

Malah sehingga September 1875 , seramai 10,000 orang tentera Serbia telah bersiakp sedia untuk melancarkan serangan ke atas kerajaan Uthmaniyah di Bosnia Herzegovina. ${ }^{22}$ Pada 30 Sepetember 1875, orang Serbia telah menyeberangi sempadan dengan kelengkapan peraiatżn tentera. Pemberontak ini telah mengepung dan memusnakkan daerah Yenivarosh dan l'reboi. Sementara itu, terdapat beribu-ribu pemberontak Serb yang lain berkumpul di Tashlidgedan mengadakan turjuk perasaan terhadap kerajaan. Manakala, di Bosnia pula, keidaan semakin kritikal sehingga pemberontakan telah bertukar kepada peperangan antara Kristian Slav menentang kerajaan Uthmaniyath.

Malah, pemberontak Serbia ini turut menghasut orang kaya dari Herzegovina. supaya meringgalkan rumah dan berkumpul di Grahovo sebagai tunjuk perasaan terhadap kerajaan Uthmaniyah. Serbia telah bersedia untuk menjadikan Grahovo sebagai pusat konspirasi mereka. Bagi menjayakan rancangan tersebut, mereka telath membakar rumahrumah dan memaksa orang ramai mengikut mereka.

Selain itu, Serbia juga telah mendapatkan bantuan antarabangsa daripada kuasa besar Rusia dalam usahanya untuk menjatuhkan kerajaan Uthmaniyah. Bahkan Serbia telah berjaya mendapatkan bantuan latihan ketenteraan daripada Rusia untuk melatih pemberontak Serbia menentang kuasa Uthmaniyah di Bosnia. Selain itu, Serbia turut berjaya mendapatkan pelbagai bantuan lain daripada Rusia seperti bantuan kewangan, senjata dan ubat-ubatan dalam usahanya menggiatkan pemberontakan di Bosnia Herzegovina. Rusia dengan mudah membantu Serbia kerana kedua-duanya mempunyai ikatan yang erat dari segi agama dan rumpun bangsa. Kedua-duanya adalah penganut kepada agama Kristian Ortodok dan terdiri daripada 
rumpun Slav Yang sama. Malah Rusia diangstap scbagai penyelamat kepada bangsia Slax dan penganut Ortodok di Balkan.

Namun begitu, atas nasihat kuasa-kuasa besar, agar keamanan dapat dipulibkan semula di Bosnia Herzegovina, Serbia telah diminta supaya tickak memberikan lekanan kepada kerajaan Uthmaniyah. Kuasa-kuasa besar yang lain seperti Britain, Jerman, Perancis dan ltali telah meninta supaya Rusia tidak membantu Serbia menentang kerajaan Uthmaniyah di Bosnia, di samping menasihati Serbia supaya menghentikan kegiatan pemberontakan tersebut. Oleh itu, Serbia terpaksa memberikan jaminan kepada Rusia dan kuasa-kuasa besar Fropah bahawa Serbia akan berkecuali dalam masalah di Bosnia Herzegovina untuk tempoh masa tertentu. Namun begitu, dalam tempol tersebut, Serbia telah membuat persiapan untuk melancarkan peperangan terhadap kerajaan Uthmaniyah pada tahun 1876.

\section{Kesimpulan}

Asas kelemahan pentadbiran kerajaan Uthmaniyah yang dikaitkan dengan kebangkitan pemberontakan di Bosnia Herzegovina pada tahun 1875 adalah tidak tepat. Sebaliknya, ini sebenarnya adalah angkara yang berpunca daripada rancangan Serbja.

" lt is a great mistake to attribute this insurrection entirely to Turkish misrule. The people have been persuaded and forced to rise by Servian and Montenegrin political intriguers, swo will not now perrit their misguided victims to act otherwise than they think fit." ${ }^{23}$

Jelas, bahawa pemberontakan 1875, bukarlih atas sebab faktor dalaman di Bosnia Herzegovina ataupun kelemahan kerajaan Uthmaniyah. Ternyata, Serbia telah memainkan peranan yang penting dalam mencetuskan kebangkitan di Bosnia Herzegovina di kalangarn orang Kristian supaya menentang Kerajaan Uthmaniyah. Keinginan Serbia untuk menggantikan Uthmaniyah sebagai pemimpin Slav di Balkan serta cita-cita Serbia Raya, adalah antara faktor utama yang mendorong mereka untuk bertindak dan memainkan peranan penting bagi mencetuskan pemberontakan di Bosnia Herzegovina pada tahun 1875. 


\section{Nota}

I H.C. Darby, Bosnic and Hercegovina, dlm. Stephen Clistold (pnyt.), A Silort history of Yisostavia, New York: Cambridge University Pruss, 1966. lilm. 38 .

2 Roger Portal, Th' Slars, Ter. Patrick Evans, London: Weidenfeld and Nicolson 1.td, 1969, hlm. 1.

* Perang lerselput mengambil nama 'Kusovo', adalah sempena nama tempat yang berlakınya pertempuran antara tentera Uthmaniyah dengan terntera Serbia di Kosovo, iaitu salah salu wilayah di Semenanjung Balkan.

- lbid, hlm. 31

5 Surat Consul Holmes kepada Earl of Derby, Doc. 7, Bosma-Serai, 2 Julai 1875, dim. D. Gillard (pnyt.), British Documetts on Fordign Affirs (BDFA): Reports and Papers from Hit' Foreghn Office Confidential Print, Britain: University Publication of America, 1984, Jart 1, Vol. 2, hlm. 53.

- Surat Consul Holmes kepada Earl of Derby, Doc. 8 Bosna-Serai, 9 Julai 1875. November 1876, dlm. D. Gillard (pnyt.), British Doctments on Foreign Affairs (BDFA), hlm. 54 .

7 Surat Consul Holmes kepada Earl of Derby, Doc. 15, Bosnia-Serai, 24 Julài 1875, dlm. D. Gillard (pnyt.), British Doctments on For'ign Affairs (BDFA), hlm. 58.

\& Ibid.

$\checkmark$ Ibid.

14 Surat Acting Consul Freeman kepada Sir H. Elliot, Doc. 42, Bosnia-Serai, 21 Ogos 1875, dlm. D. Gillard (pnyt), British Decuments on Forrign Affairs (BDFA), hlm. 72 .

1 Surat Consul Holmes kepada Earl of Derby, Doc. 54, Mostar, 22 Ogos 1875, dlm. D. Gillard (pnyt.), British Documents on Fortign Affairs (BDFA), hlm. 77-78.

12 Petikan daripada surat berhubung dengan reformasi pentadbiran di Bosnia. Doc 1. November 1876, dlm. D. Gillard (pnyt), British Documents on Foreign Affars (BDFA), hlm. 38 .

Ibid, hlm. 36.

it Ibid, hlm. 37.

15 Strat Sir A. Buchanan kepada Earl of Derby, Doc. 47, Constantinople, 1 September 1875, dim. D. Gillard (pnyt.), British Documents on Forejign Affairs (BDFA), him. 74 .

10 Petikan daripada surat berhubung dengan reformasi pentadbiran di Bosnia. Doc 1. November 1876, dlm. D. Gillard (pnyt), British Documenis on Foreign Affairs (BDFA), him. 4.

17 Surat Consul Holmes kepada the Earl of Derby, Doc 85, Mostar, September 24, 1875, dlm. D. Gillard (pnyt), British Doctumts on Foreign Affairs (BDFA), him. 94. 
18 Petikan daripada surat berhubung dengan reformasi pentadbiran di Bosnia. Doc 1. November 1876, dJm. D. Gillard (pnyt.), British Doctments
ont Fortign Affairs (BDFA), hlm. 36.

1* Surat Consul General White kepada Farl of Derby, Doc. 29, Belgrade, 23 Ogos 1875, dlm. D. Gillard (pnyt), British Documents on Foreign Affairs (BDFA), hlm. 65.

20 Surat Consul General White kepada Earl of Derby, Doc. 37, Belgrade, 20 Ogos 1875, dlm. D. Gillard (pnyt.), British Documents on Foreign Affairs
(BDFA), hlm. 69 .

21 Surat Consul Taylor kepada Earl of Derby, Doc. 58, Ragusa, 23 Ogos 1875, dlm. D. Gillard (pnyt.), British Documents on Foreign Affaits
(BDFA), hlm. 81 .

22 Surat Consul General White kepada Sir H.Elliot, Doc. 103, Belgrade, 27 September 1875, dlm. D. Gillard (pnyt.), British Documents on Foreign Affairs (BDFA), hlm. 101.

23 Surat Consul Holmes kepada Sir H.Elliot, Doc. 86, Mostar, 10 Seplember 1875, dlm. D. Gillard (pnyt.), British Documents on Foreign Affairs (BDFA), Part 1, Vol. 2, hJm. 95. 